\title{
Impact of Smart Electric Thermal Storage on Transmission Grid Limitations
}

\author{
Antans Sauhats, Sergey Kovalenko, Karlis Baltputnis, Zane Broka, Inga Zicmane \\ Institute of Power Engineering \\ Riga Technical University \\ Riga, Latvia \\ sauhatas@eef.rtu.lv, sergejs.kovalenko@rtu.lv, karlis.baltputnis@rtu.lv, zane.broka@rtu.lv, zicmane@eef.rtu.lv
}

\begin{abstract}
This paper examines the potential benefits smart and quickly controllable load can provide for transmission network congestion management if end-users give the transmission network operator or an independent aggregator service access to disconnect their devices in case of contingencies. The necessary amount of available quickly controllable load for the fulfilment of $\mathrm{N}-1$ criteria is found for the case study of the Latvian power system. Of particular interest is the possibility to increase the maximum available transfer capacity between the Latvian and Estonian bidding areas by removing the $\mathrm{N}-1$ provision from the calculation of the cross-border trading capacity if it can be supplied by the controllable load instead. For this purpose, a steady-state power flow model of the $330 \mathrm{kV}$ transmission network and its interconnections with neighboring countries is used for simulations.
\end{abstract}

Keywords-congestion management; load flow; thermal storage; transfer capacity; transmission network

\section{INTRODUCTION}

Energy market liberalization in Europe had the purpose of increased competition between power producers and, subsequently, improved overall efficiency of the power systems. This was ultimately supposed to provide the end-consumers with cheaper electricity as the most cost-effective producers ought to prevail [1]. While to some degree the goals have been largely achieved, there are nevertheless still several obstacles to an entirely integrated market; most importantly - the limited transmission capacities between several European countries and in some cases even among different areas within the same country. These constrained interconnectors cause bottlenecks that limit the flow of cheaper electricity from areas with surplus power. Consequently, more expensive generators become the marginal, price-setting units in the deficit areas.

Thereby, it can be argued that it is beneficial for the transmission system operator (TSO) to seek for ways to increase the cross-border capacities available for trading. The most obvious solution is grid reinforcement or construction of new interconnectors. However, this requires sizable investments. Alternatively, some smaller increases can also be achieved by changing the way cross-border trading capacity is allocated. A common practice of TSOs is to account for possible N-1 contingencies when calculating the cross-zonal net transfer capacity, i.e., if any of interconnectors between two countries or areas is unexpectedly disconnected, the remaining connections

The work presented in this paper has been co-financed by the National Research Program LATENERGI (2014-2017). should be able to carry the scheduled power. In this paper, we consider the possibility to allocate the trading capacity disregarding the N-1 criterion, i.e., solely based on the thermal rating of the lines.

Generally, there are two strategies on how to handle contingencies in such a scenario - by readjusting either generation or load. However, it can take up to a minute to increase power production in the case of a sudden interconnector disconnection even if spinning reserve has been provided. On the other hand, if a significant proportion of the load is equipped with communications and control equipment that allows for near instantaneous switching off, the desired effect is achieved faster and without the need to pay for generation reserve activation. This type of post-contingency corrective action is applied to real-life based case studies of the Latvian power system in this paper.

Of course, the effect load disconnection, even if just occasional, has on the end-users' comfort and daily routine ought to be minimized. A suitable device for this might be thermal storage heaters for domestic hot water or space heating. Smart electric thermal storage (SETS) allows to decouple the power demand of the heating system from the time of thermal energy end-use by the domestic customer [2], [3]. The remote deactivation of the charging cycle of a SETS device will thus not cause immediate discomfort to the occupants of a dwelling thanks to both, the energy they have managed to store before the command and the thermal inertia of the building.

While direct resistive or storage electric heating is not widespread in Latvia, $31.5 \%$ of dwellings do use electric hot water heaters [4]. If we assume the average power of one hot water storage heater to be $3 \mathrm{~kW}$, then based on the total number of dwellings equal to 804.9 thousand [4], we can estimate the total installed power of flexible water heaters to reach about $2400 \mathrm{MW}$ if all of the domestic hot water is provided by smart heaters, and $760 \mathrm{MW}$ if all currently deployed electric water heaters are replaced.

On the other hand, estimating the full potential of SETS space heaters in Latvia is harder as there is barely any electric space heating to replace, thereby the total potentially installed capacity of SETS devices depends on the assumptions. A preliminary estimation can be done based on the average heat demand in residential multi-apartment buildings 
(139.34 kWh $/ \mathrm{m}^{2}$ annum in 2016 [5]) and the total floor space of housing stock in Latvia (74.7 million $\mathrm{m}^{2}$ in 2015 [6], which results in the total annual heat consumption of $10408.7 \mathrm{GWh}$.

A local, distributed small-scale storage system can provide overall societal benefits, such as cost savings to the customers or renewables curtailment reduction, whereas the aggregated load can offer a number of services to the power system such as demand shifting and demand response, ancillary services (frequency response, reserves provision), congestion management and deferral of capital investments into the network [3]. It is suggested that demand response may be more efficient and even more reliable in providing reserves than conventional generators [7]. Besides, it can help to reduce dependence on power import and export through interconnections to neighboring regions [7] and improve transmission grid investment and operation efficiency [8]. The system could be operated at lower costs and with reduced network and generation capacity, provided that overloads occurring after outages can be effectively eliminated by curtailing flexible loads with enabled demand response [8].

While heating electrification with SETS at such a large scale brings new flexibility options for the power system, it should be nevertheless approached with caution in terms of the capability of the transmission and distribution network to accommodate the additional load. However, this aspect is not addressed in the present study and will be subject of our future work. This paper is instead focused on investigating employment of flexible load such as SETS for cross-border congestion management to maximize the net transfer capacity for importing the surplus power from Estonia to Latvia.

The remaining part of the paper is organized as follows. In section II, the Baltic power system is briefly characterized. Section III presents the model of the transmission system to be used in case studies. Section IV reports the results followed by conclusions.

\section{PeCuliarities of the LatVian Power System}

As the case studies analyzed in this paper are based on the Latvian power system and its connections to Estonia, it is important to consider the main characteristics of the electricity transmission infrastructure in the region.

\section{A. Generation and Transmission Capacities}

Approximately $88 \%$ of the generation capacity in Latvia is comprised by a cascade of three run-of-river and poundage hydropower plants (HPP) with total installed generation capacity of $1560 \mathrm{MW}$, and two natural gas combined heat and power (CHP) plants in Riga (electrical capacity $1025 \mathrm{MW}$, thermal generation capacity $689 \mathrm{MW}$ ). The two CHP plants supply district heating for roughly half of the dwellings in Riga. Thus, while the operation of HPPs is mostly determined by water inflow, the operation of CHP plants is largely based on thermal energy demand. Electricity market price, of course, is another important factor influencing the operation of all units.

The Latvian power system is connected to Lithuania, Estonia and Russia. Statistics show that the direction of cross-border flows is usually from Estonia to Latvia and from Latvia to Lithuania. The links to Estonia are particularly important as they

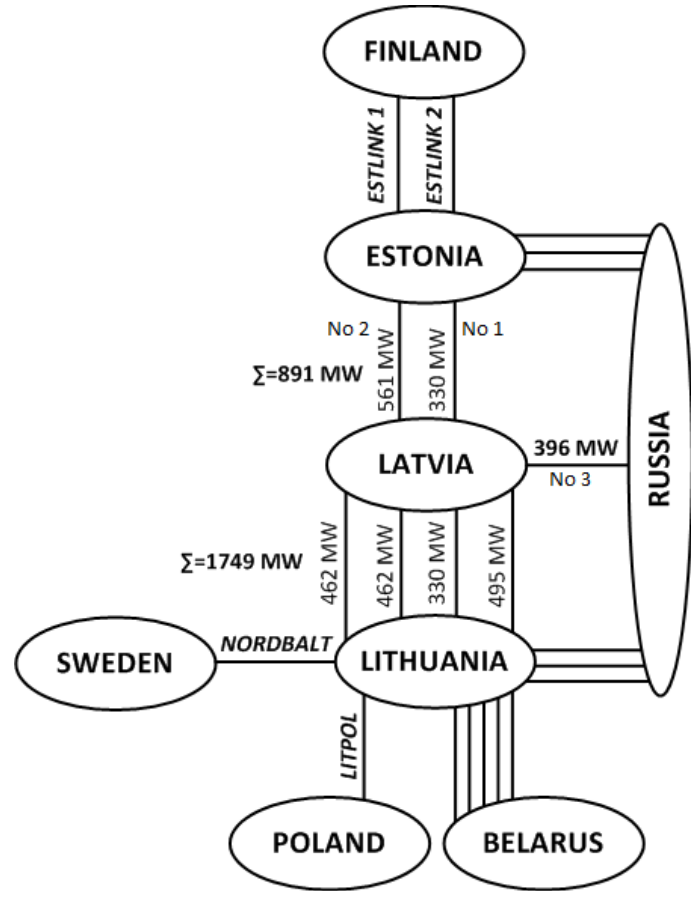

Fig. 1. Cross-border transmission capacities between the Baltic states and their neighbors

can often provide cheaper electricity. The transmission capacities between Latvia and its neighboring countries are shown in Fig. 1.

In regard to contingency management, it must be noted that the pumped storage hydropower plant (PSHP) in Kruonis, Lithuania, is a source of flexible generation and load for all the Baltic states including Latvia as it can be ramped up or down significantly faster than many other power plants. Namely, the Kruonis PSHP plant can reach its full rated power output (900 MW) in about 2 minutes. There are 4 units each of which has a range of $0-225 \mathrm{MW}$ in generator mode and a fixed capacity of $220 \mathrm{MW}$ in pumping mode [9].

In Latvia, the fastest local regulation from the generation side can be provided by the HPPs as their individual hydroelectric unit ramp rates range from 3.3 to $7.5 \mathrm{MW} / \mathrm{s}$ resulting in $122 \mathrm{MW} / \mathrm{s}$ for the whole HPP cascade. The large cogeneration plants, on the other hand, are much more inflexible with individual ramp rates of $8.2-16.7 \mathrm{MW} / \mathrm{min}$ totaling in 41.6 MW/min for the both Riga CHP plants.

With that in mind, we propose employing quickly controllable load in combination with automatic overload control of lines as an alternative source of flexibility to increase the transfer capacity between Estonia-Latvia (lines No 1and 2, Fig. 1) and Russia-Latvia (line No 3) to the maximum technically feasible limit. Due to peculiarities in asset ownership and market structure, the line No 3 is also usually employed in trade between Nord Pool participants. Increasing the transmission capacity is beneficial to the local consumers when electricity prices differ in Estonia and Latvia. 


\section{B. Comparison of the Baltic Countries' Price Areas}

As of June 2013, Latvian producers and wholesalers trade electricity in the Nord Pool power exchange which is a market combining the Baltic and Nordic countries. If we compare the price dynamics in the Baltics states since then [10], two observations become evident:

- the Latvian and Lithuanian power systems are wellconnected and bottlenecks between them are rare (Table I);

- the Estonian and Latvian links, however, reach their full allocated trading capacity fairly often (e.g., $29 \%$ of hours in 2016), which is signified by the formation of different area prices in both countries (Table II); furthermore, the price in Latvia tends to reach higher levels in these situations than in its northern neighbor.

TABLE I. COMPARISON OF LITHUANIAN AND LATVIAN PRICE AREAS

\begin{tabular}{|l|c|c|c|c|}
\hline \multicolumn{1}{|c|}{ LT-LV } & $\mathbf{2 0 1 4}$ & $\mathbf{2 0 1 5}$ & $\mathbf{2 0 1 6}$ & $\mathbf{2 0 1 4 - 2 0 1 6}$ \\
\hline average price diff., $€ / \mathrm{MWh}$ & 3.01 & 8.72 & 13.44 & 8.39 \\
\hline $\begin{array}{l}\text { min. price diff. (nonzero), } \\
€ / \text { MWh }\end{array}$ & 0.08 & 0.02 & -8.90 & -8.90 \\
\hline $\begin{array}{l}\text { max. price diff., } \\
\text { €/MWh }\end{array}$ & 7.34 & 60.36 & 106.15 & 106.15 \\
\hline $\begin{array}{l}\text { hours when price is } \\
\text { different, number }\end{array}$ & 30 & 74 & 262 & 366 \\
\hline $\begin{array}{l}\text { hours when price is } \\
\text { different, \% }\end{array}$ & 0 & 1 & 3 & 1 \\
\hline
\end{tabular}

TABLE II. COMPARISON OF LATVIAN AND ESTONIAN PRicE AREAS

\begin{tabular}{|l|c|c|c|c|}
\hline \multicolumn{1}{|c|}{ LV-EE } & $\mathbf{2 0 1 4}$ & $\mathbf{2 0 1 5}$ & $\mathbf{2 0 1 6}$ & $\mathbf{2 0 1 4 - 2 0 1 6}$ \\
\hline average price diff., $€ / M W h$ & 17.96 & 16.29 & 10.40 & 14.88 \\
\hline $\begin{array}{l}\text { min. price diff. (nonzero), } \\
€ / M W h\end{array}$ & 0.01 & 0.01 & -43.90 & -43.90 \\
\hline $\begin{array}{l}\text { max. price diff., } \\
€ / M W h\end{array}$ & 256.01 & $\begin{array}{c}173.8 \\
2\end{array}$ & 172.31 & 256.01 \\
\hline $\begin{array}{l}\text { hours when price is } \\
\text { different, number }\end{array}$ & 6099 & 5787 & 2546 & 14432 \\
\hline $\begin{array}{l}\text { hours when price is } \\
\text { different, \% }\end{array}$ & 70 & 66 & 29 & 55 \\
\hline
\end{tabular}

\section{METHOD}

Ultimately, the goal of our study is to develop a tool which allows for a thorough evaluation of the benefits that SETS as a flexible load could bring to the power system in terms of interconnector adequacy and investment deferral. The model and results described in this paper form an important building block of the overall tool under development. While the power system of Latvia is relatively small, it nevertheless contains thousands of elements. Thereby assumptions have to be made that allow simplification of the task at hand in order to achieve reasonable computational burden.

The following assumptions are proposed and adopted for simplification of the power system model:

1. Operation of $110 \mathrm{kV}$ and lower voltage networks is not modelled. It is assumed that all the load is connected to the $330 \mathrm{kV}$ network instead. In future work the losses in lower voltage networks will be included by upscaling the estimates obtained from representative feeder networks.

2. Static and dynamic stability of the system is not tested. This assumption is motivated by the structure and parameters of the Latvian high-voltage network and the existence of highly sophisticated automation equipment. Analysis of the simulated system contingencies shows that thermal overload of highvoltage transmission lines occurs before the loss of either static or dynamic stability. Only due to highly rare coincidental contingencies (short-circuit and failure of the primary and backup protection) an out-of-step mode may occur, which is then swiftly eliminated by dedicated out-of-step automation [11].

The mathematical model of the Latvian $330 \mathrm{kV}$ transmission network was implemented in the ETAP PowerStation. The model also considers import and export capabilities with EE, RU and LT. Besides, a MATLAB model was created and validated against the ETAP model. The difference in results between both of those did not exceed $1.7 \%$, showing that in future work the MATLAB model can be confidently used instead of ETAP, which is important to integrate it with other models and carry out a large number of simulations.

The final tool (Fig. 2), which is a work in progress, will also include the models of largest hydro and thermal power plants (by solving the unit commitment problem), power and heat demand, ambient temperature and water inflow records database, and controllable load model in an hourly resolution for a horizon of at least a year.

In the current step, we can find the voltage at nodes and power flow in lines in Latvia by setting the generation and load in nodes, the topology of the network and ampacity ratings of lines (as constraints). The actual power flow should not exceed the line carrying capacity and the voltage at nodes should be within $+/-5(10) \%$ of the nominal $330 \mathrm{kV}$.

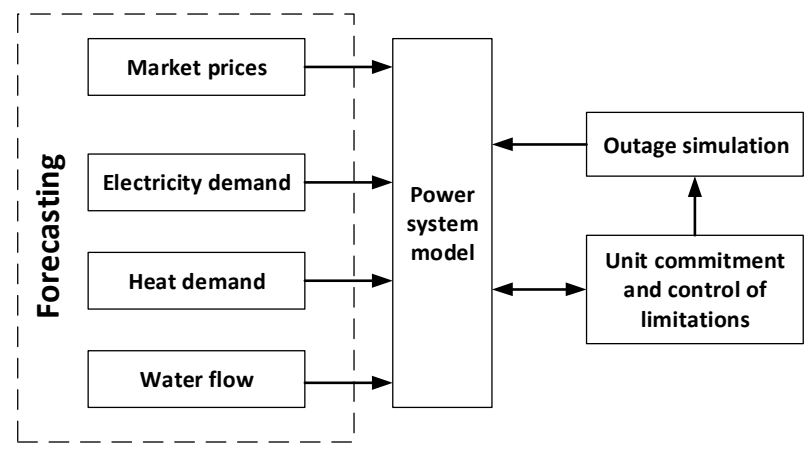

Fig. 2. The overall modelling task

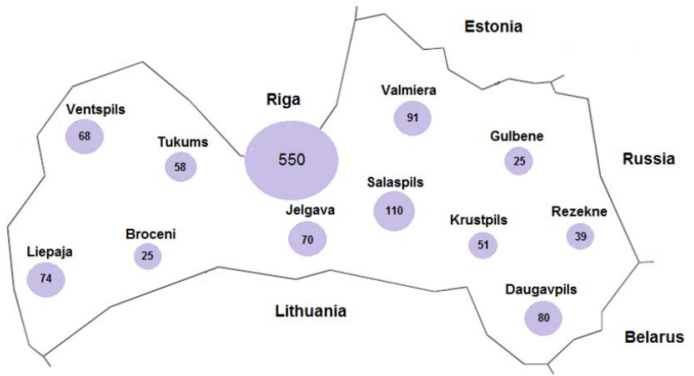

Fig. 3. Average load (MW) in Latvian cities 


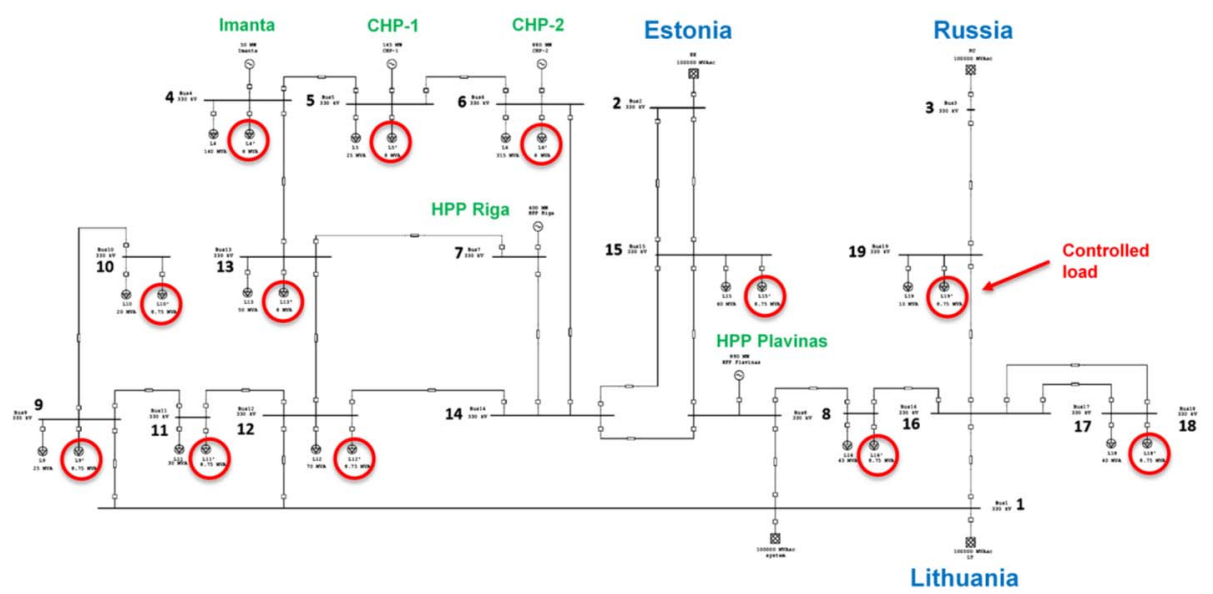

Fig. 4. Model of the Latvian $330 \mathrm{kV}$ transmission network in ETAP PowerStation

TABLE III. SUMMARY OF THE CASE STUDIES

\begin{tabular}{|c|c|c|c|c|c|c|c|c|c|}
\hline $\begin{array}{l}\text { Case } \\
\text { No. }\end{array}$ & $\begin{array}{l}\text { Generation } \\
\text { in } \mathrm{LV}, \mathrm{MW}\end{array}$ & $\begin{array}{c}\text { Transit EE- } \\
\text { LV and RU- } \\
\text { LV, MW }\end{array}$ & $\begin{array}{c}\text { Transit LV- } \\
\text { LT, MW }\end{array}$ & $\begin{array}{c}\text { Consumption } \\
\text { in } \mathrm{LV}, \mathrm{MW}\end{array}$ & $\begin{array}{l}\text { Disconnected } \\
\text { line flow, MW }\end{array}$ & $\begin{array}{c}\text { Disconnected } \\
\text { controllable } \\
\text { load, MW }\end{array}$ & $\begin{array}{c}\text { System } \\
\text { balance, MW }\end{array}$ & $\begin{array}{l}\text { Contin- } \\
\text { gency }\end{array}$ & $\begin{array}{l}\text { Post-contingency corrective } \\
\text { action }\end{array}$ \\
\hline 0 (ref.) & 710 & 790 & 570 & 930 & 0 & - & 1500 & - & - \\
\hline $1(\max )$ & 213 & 1390 & 673 & 930 & 0 & - & 1603 & - & $\begin{array}{c}\text { decrease generation in LV } \\
\text { compared to Case No. } 0\end{array}$ \\
\hline 2 & 213 & 1083 & 682 & 614 & 307 & 316 & 1296 & $\mathrm{~N}-1$ & $\begin{array}{c}\text { decrease consumption in LV } \\
\text { compared to Case No. } 1\end{array}$ \\
\hline 3 & 213 & 668 & 676 & 205 & 675 & 725 & 881 & N-1 & $\begin{array}{l}\text { decrease consumption in LV } \\
\text { compared to Case No. } 1\end{array}$ \\
\hline 4 & 213 & 981 & 684 & 510 & 408 & 420 & 1194 & N-1 & $\begin{array}{c}\text { decrease consumption in LV } \\
\text { compared to Case No. } 1\end{array}$ \\
\hline
\end{tabular}

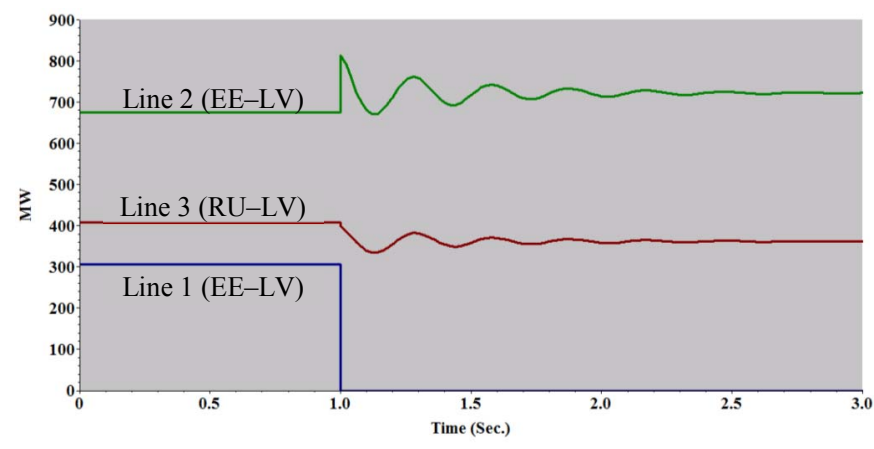

Fig. 5. Active power flow of interconnectors in Case No. 2

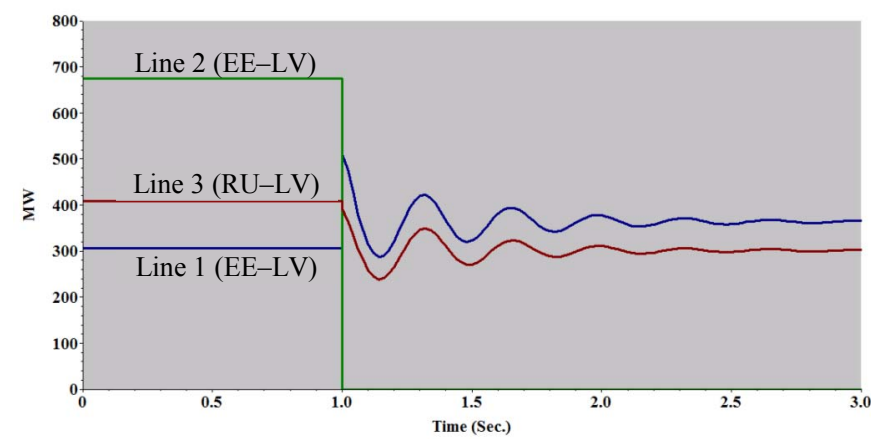

Fig. 6. Active power flow of interconnectors in Case No. 3

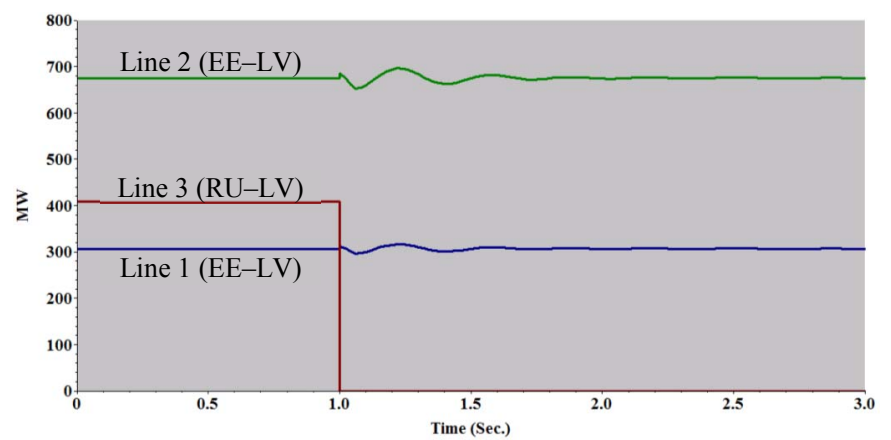

Fig. 7. Active power flow of interconnectors in Case No. 4

\section{CASE STUDY}

The transmission model developed in ETAP (Fig. 4) was used to analyze several N-1 contingencies and to evaluate the amount of controllable load necessary to fully exploit the power lines in operation. In scenarios $2-4$, one of the northern interconnectors was disconnected reducing the import capability to Latvia. We assume that the local Latvian generation cannot be increased for balancing purposes and only the load can be adjusted. This is necessary to assess particularly the operation of controllable load. Additionally, we assume that the available controllable load is distributed among the transmission network nodes based on the statistical average loading in each region (Fig. 3). 
Case No. 0: reference mode, constructed closely to the data available from Nord Pool. The purpose of this is to find reference values for the total load in Latvia and flows to Lithuania. The maximum available interconnector capacities by thermal rating on the northern border (Fig. 1) are as follows: the $1^{\text {st }}$ line $(\mathrm{EE}-\mathrm{LV})-367 \mathrm{MW}$, the $2^{\text {nd }}$ line $(\mathrm{EE}-\mathrm{LV})-809 \mathrm{MW}$ and the $3^{\text {rd }}$ line (RU-LV) $-477 \mathrm{MW}$. The calculations show that $\mathrm{N}-1$ criterion is fulfilled in this configuration for cross-border flows at $30-60 \%$ of the maximum even if no controllable load is available.

Case No. 1: let us assume that the section EE-LV and RULV is highly loaded (above $80 \%$ ). We implement this by decreasing the generation in Latvia. In this scenario, generation in $\mathrm{LV}$ is $213 \mathrm{MW}$ (70\% less compared to the Case No. 0), the load remains $930 \mathrm{MW}$ as before. In this case criterion N-1 is not achieved without controllable load. In continuation, we will find the volume of controllable load required for the fulfilment of criteria.

The power flows of lines to be disconnected in the next scenarios to examine three different $\mathrm{N}-1$ contingencies are: the $1^{\text {st }}$ line $-307 \mathrm{MW}$, the $2^{\text {nd }}$ line $-675 \mathrm{MW}$, the $3^{\text {rd }}$ line $-408 \mathrm{MW}$.

Case No. 2: let us assume that the $1^{\text {st }}$ line has been disconnected due to a fault. The line with Russia and one line with Estonia remain in operation. The modelling results in ETAP PowerStation show that in order to fulfil the N-1 criterion and maintain thermal stability, $316 \mathrm{MW}$ of controllable load have to be switched off. In this case, the power carried by the $2^{\text {nd }}$ line equals $721 \mathrm{MW}$ and by the $3^{\text {rd }}$ line $-362 \mathrm{MW}$. These values do not violate the thermal ratings (Fig. 5).

Case No. 3: the $2^{\text {nd }}$ line is disabled. In this case $725 \mathrm{MW}$ of controllable load has to be disconnected. The flow in the $1^{\text {st }}$ line is now $366 \mathrm{MW}$, and $302 \mathrm{MW}$ in the $3^{\text {rd }}$ line. Once again, the thermal ratings have not been violated (Fig. 6).

Case No. 4: in the event of disconnection of the $3^{\text {rd }}$ line, it is required to switch off $420 \mathrm{MW}$ of the controlled load. The flow in the $1^{\text {st }}$ line is now $306 \mathrm{MW}$ and in the $2^{\text {nd }}$ line $-675 \mathrm{MW}$. Line thermal ratings are still respected (Fig. 7).

In addition, while studying the maximum load mode (Case No. 1), it was found that by increasing the share of controllable load available for congestion management in Latvia by $10 \%$, the interconnector capacity of EE-LV and RU-LV can be increased by $7.1 \%$ to a limit of $100 \%$ which corresponds to line thermal ratings.

For additional results, we refer to the previous study [12] where the compliance with $\mathrm{N}-1$ and $\mathrm{N}-2$ criteria as well as stability of the power system with a proportion of load being controllable was examined.

\section{CONCLUSIONS}

With reliably and quickly controllable load, it is possible to increase the usage efficiency of power transmission lines and gain more benefit from electricity market mechanisms by removing the $\mathrm{N}-1$ provision from the calculation of cross-border trading capacity and maintaining it by means of the controllable load instead.

1. The results can be roughly summarized by concluding that every $10 \%$ of controllable load in Latvia available in the case of an outage allows to increas the cross-border capacity with Estonia by $7.1 \%$.

2. The effect of the controllable load on the stability of the Latvian energy system is insignificant.

3. Three lines of the northern section connecting Latvia to Estonia and Russia can be loaded up to almost $100 \%$, provided that specific automation equipment is installed at appropriate locations in Latvia.

4. The volume of controllable load that has to be disconnected in case of an interconnector outage is about $3-7 \%$ higher than the pre-contingency flow in the disconnected line.

5. Increased maximum allowed trading capacity in the three lines of the northern section will allow Latvia to buy more energy from Estonia and further decrease the number of hours when the price in Latvia is higher due to congestions, thus enhancing market integration.

\section{REFERENCES}

[1] "Directive 2009/72/EC of the European Parliament and of the Council of 13 July 2009 concerning common rules for the internal market in electricity and repealing Directive 2003/54/EC," Off. J. Eur. Union, vol. 52, p. L 211/55-93, 2009.

[2] A. McDonald, “Thermal Storage Device," US 2015/0055941 (A1), 2015.

[3] J. Raadschelders, F. Sikkema, and B. in't Groen, "Potential for Smart Electric Thermal Storage. Contributing to a low carbon energy system," Arnhem, 2013.

[4] "Data portal of the Central Statistical Bureau of Latvia." [Online]. Available: http://data.csb.gov.lv.

[5] "Average specific heat demand up to March 1, 2017." [Online]. Available: http://bvkb.gov.lv/lv/content/videjais-ipatnejais-apkurespaterins-lidz-01032017.

[6] N. Ritter et al., "Market review report: socio-economic \& housing trends in selected countries," 2016. [Online]. Available: http://www.realvalueproject.com/images/uploads/documents/RealValue Market_Review_Report.pdf

[7] N. O'Connell, P. Pinson, H. Madsen, and M. O'Malley, "Benefits and challenges of electrical demand response: A critical review," Renew. Sustain. Energy Rev, vol. 39, pp. 686-699, 2014.

[8] G. Strbac, "Demand side management: Benefits and challenges," Energy Policy, vol. 36, no. 12, pp. 4419-4426, 2008.

[9] "Kruonis PSHP." [Online]. Available: https:/gamyba.le.lt/en/activities/electricity-generation/kruonis-pumpedstorage-hydroelectric-plant-kpshp.

[10] "Nord Pool price statistics." [Online]. Available: http://nordpoolspot.com.

[11] A. Sauhats, A. Utans, D. Antonovs, and A. Svalovs, "Angle ControlBased Multi-Terminal Out-of-Step Protection System," Energies, vol. 10, no. 3, p. 308, Mar. 2017.

[12] S. Kovalenko, A. Sauhats, and I. Zicmane, "Impact of Controlled Load on the Latvian Power System Stability," in Power and Electrical Engineering of Riga Technical University (RTUCON), 2016 57th International Scientific Conference on, 2016, pp. 1-6. 